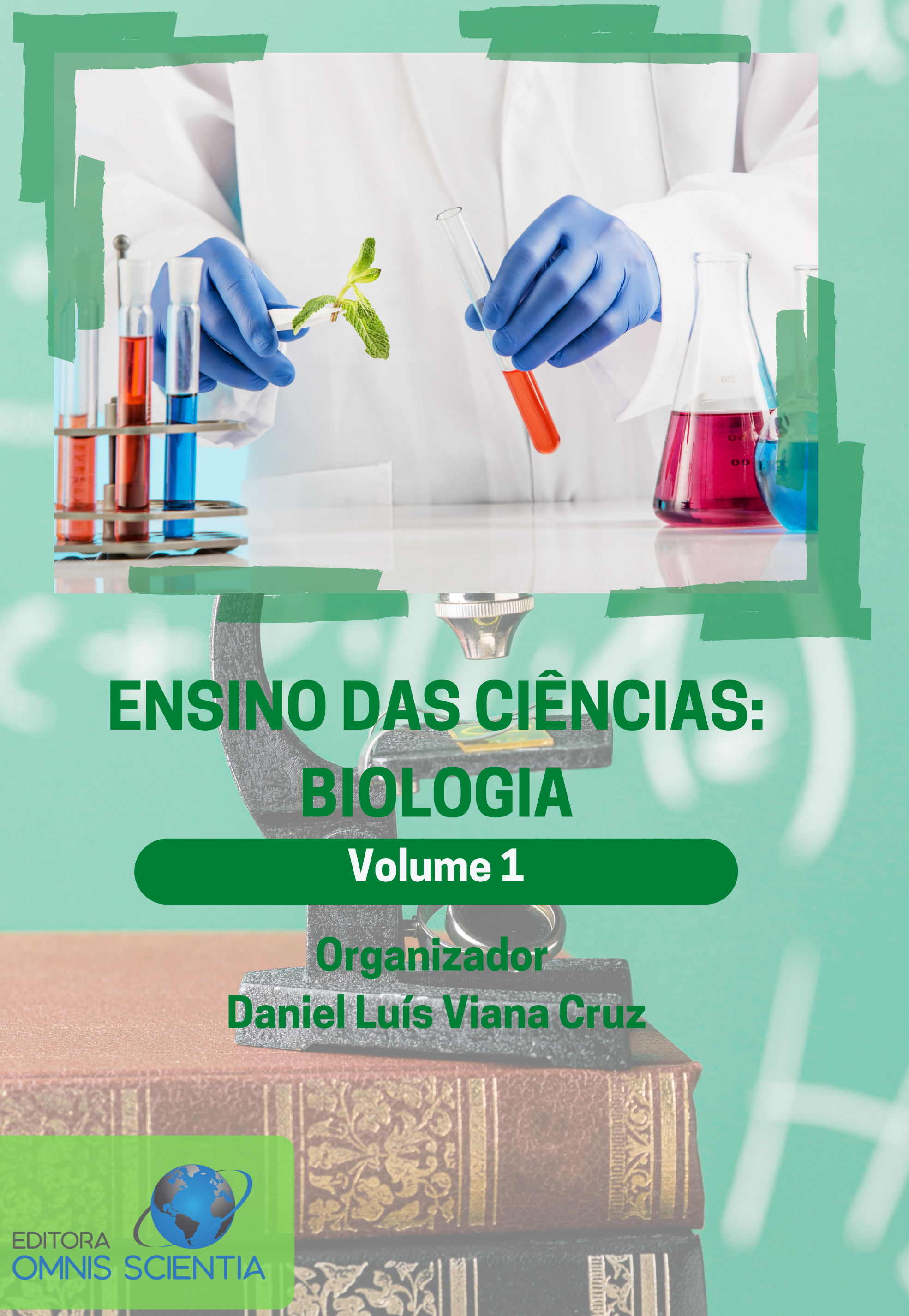




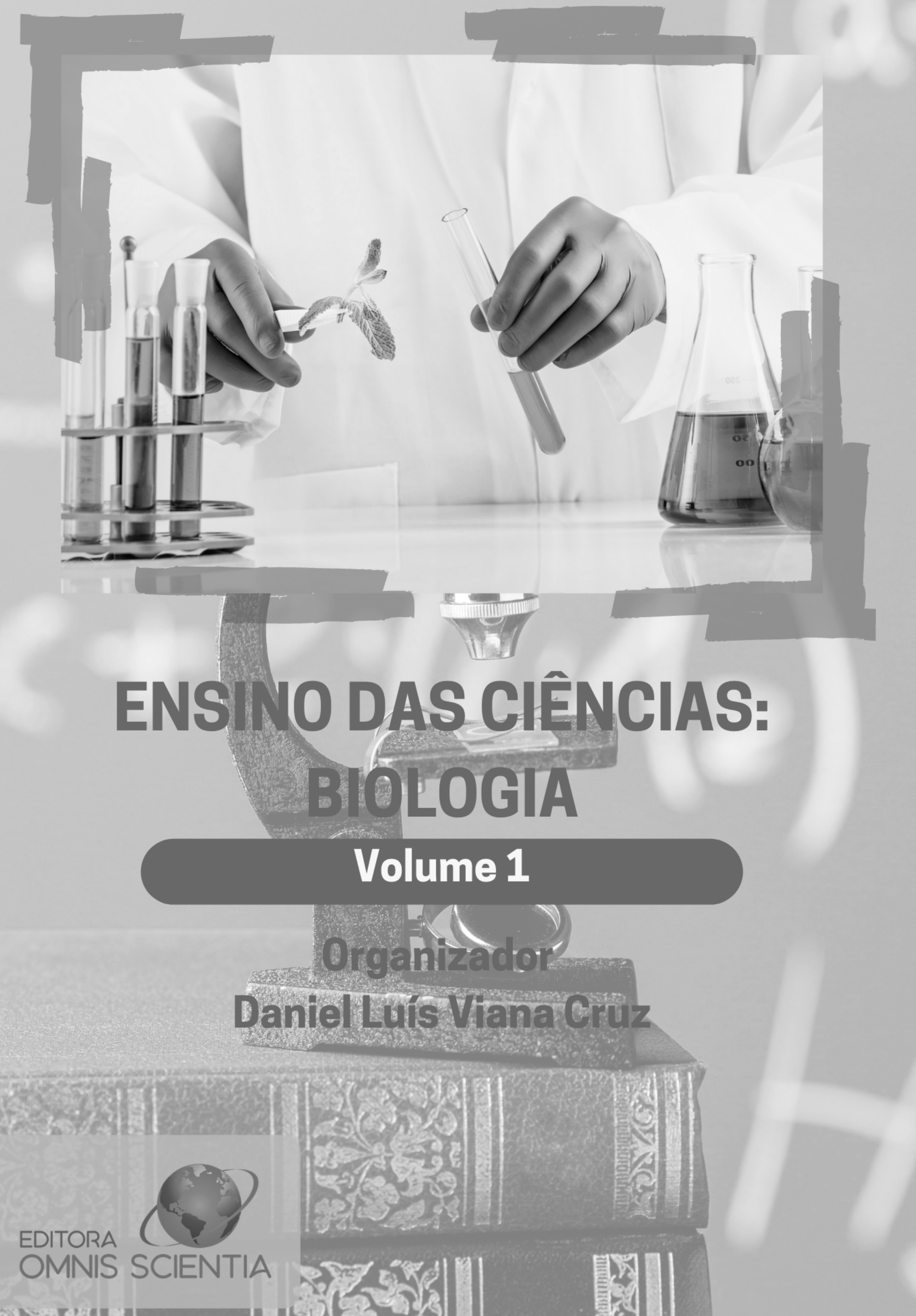


Editora Omnis Scientia

\section{ENSINO DAS CIÊNCIAS: BIOLOGIA}

Volume 1

$1^{\mathrm{a}}$ Edição

TRIUNFO - PE 


\section{Editor-Chefe}

Me. Daniel Luís Viana Cruz

Organizador (a)

Me. Daniel Luís Viana Cruz

\section{Conselho Editorial}

Dra. Pauliana Valéria Machado Galvão

Dr. Wendel José Teles Pontes

Dr. Walter Santos Evangelista Júnior

Dr. Cássio Brancaleone

Dr. Plínio Pereira Gomes Júnior

Editores de Área - Ciências Humanas

Dr. Cássio Brancaleone

Dr. José Edvânio da Silva

Assistentes Editoriais

Thialla Larangeira Amorim

Andrea Telino Gomes

Imagem de Capa

Freepik

\section{Edição de Arte}

Leandro José Dionísio

Revisão

Os autores

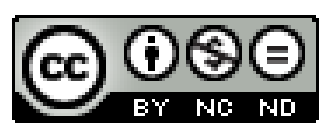

Este trabalho está licenciado com uma Licença Creative Commons - AtribuiçãoNãoComercial-SemDerivações 4.0 Internacional.

O conteúdo abordado nos artigos, seus dados em sua forma, correção e confiabilidade são de responsabilidade exclusiva dos autores. 


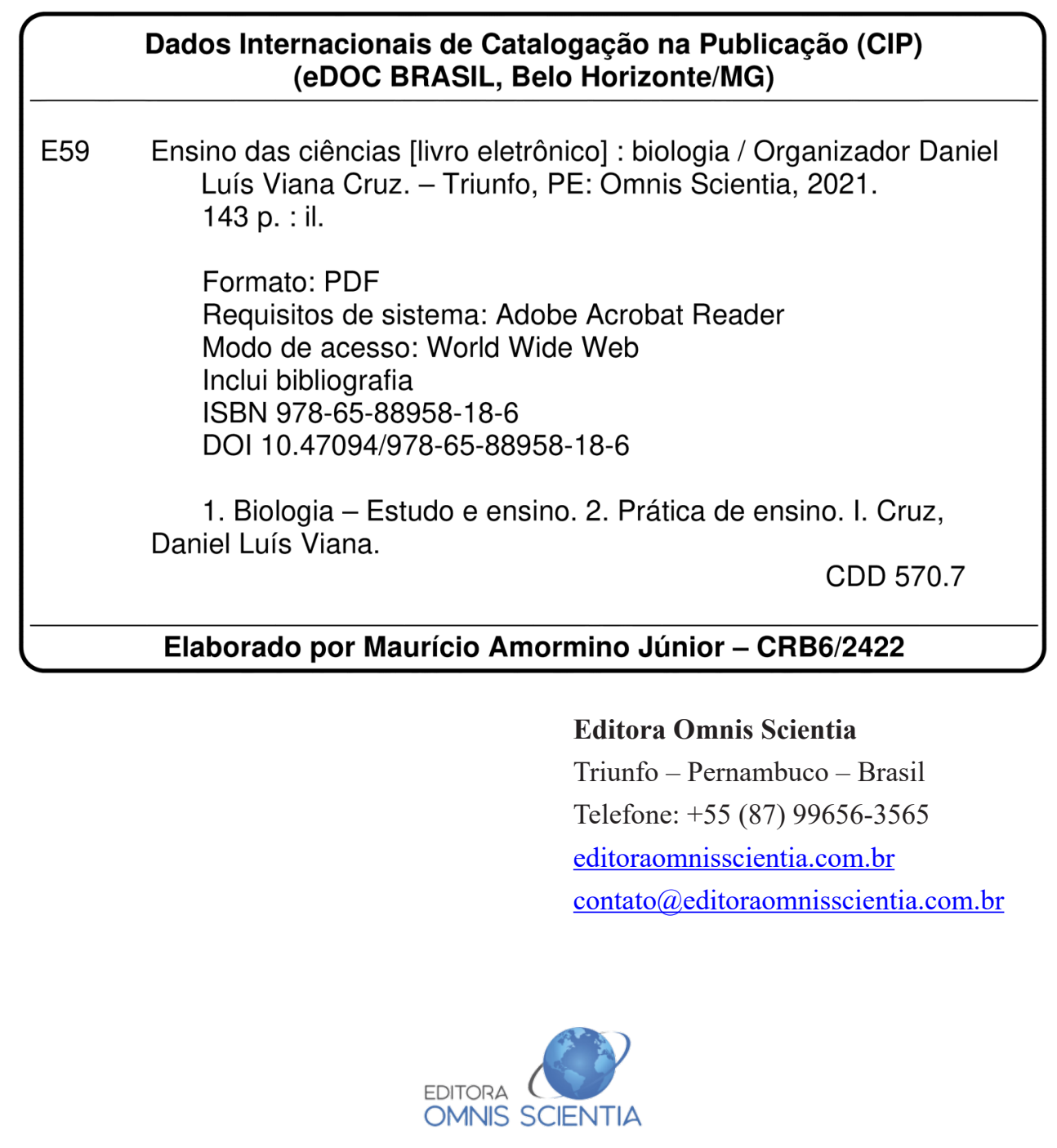




\section{PREFÁCIO}

O ensino é mais do que uma vocação, no país que vivemos trata-se de um sacerdócio. Ensinar, com poucos recursos e sem o merecido reconhecimento por parte da sociedade é persistir numa luta sem fim. Principalmente nesse período obscurecido pela desinformação e pelo negacionismo. Mas quando falamos de ensinar ciências, isso se torna ainda mais complexo, pois poucas escolas, sejam elas públicas ou privadas, possuem infraestrutura para aulas práticas. Que são tão importantes na fixação da informação. E assim os professores das ciências (Matemática, Física, Química e Biologia) seguem fazendo "mágica" nas salas de aula para que os alunos aprendam o mínimo necessário para a vida. Quando se trata de ensina Biologia, há muito que fazer com poucos recursos e o mínimo de boa vontade. E nessa obra o leitor poderá se inspirar em metodologias e ideias muito interessantes publicadas pelos autores.

Em nossos livros selecionamos um dos capítulos para premiação como forma de incentivo para os autores, e entre os excelentes trabalhos selecionados para compor este livro, o premiado foi o capítulo 3, intitulado "UM OLHAR PARA O ENFRENTAMENTO DAS VISÕES INGÊNUAS SOBRE A CIÊNCIA NO ENSINO DE BIOLOGIA”. 


\section{SUMÁRIO}

CAPÍTULO 1

AULAS REMOTAS DE CIÊNCIAS E BIOLOGIA DURANTE A PANDEMIA DO COVID-19 NA PERSPECTIVA DOS DISCENTES

Priscila Chaves de Souza

Hélio da Guia Alves Junior

DOI: $10.47094 / 978-65-88958-18-6 / 11-18$

CAPÍTULO 2 19

PRODUÇÃO E UTILIZAÇÃO DE MATERIAIS DIDÁTICOS NO ENSINO - APRENDIZAGEM DE DOENÇAS PARASITÁRIAS COMO: AMEBÍASE.

Sarah Lorena Silva Santos

Talessa Viegas Araujo

Samara Alves Correa

Lara Vitória Ribeiro Ferreia

Suelen Rocha Botão Ferreira

Lise Maria Mendes Holanda de Melo Ferreira

DOI: 10.47094/978-65-88958-18-6/19-27

CAPÍTULO 3 .28

UM OLHAR PARA O ENFRENTAMENTO DAS VISÕES INGÊNUAS SOBRE A CIÊNCIA NO ENSINO DE BIOLOGIA

Elda Cristina Carneiro da Silva;

Joanez Aparecida Aires

DOI: 10.47094/978-65-88958-18-6/28-41 
CAPÍTULO 4

ABORDAGEM DO TEMA SISTEMAS DE ENTREGA DE FÁRMACOS NO ENSINO FUNDAMENTAL

Edmilson Clarindo de Siqueira

José Adonias Alves de França

Silvana Caroline de Holanda

DOI: $10.47094 / 978-65-88958-18-6 / 42-52$

CAPÍTULO 5

A NANOTECNOLOGIA APLICADA AO ENSINO DE CIÊNCIAS

Edmilson Clarindo de Siqueira

José Adonias Alves de França

Silvana Caroline de Holanda

Fábio Rocha Formiga

DOI: $10.47094 / 978-65-88958-18-6 / 53-64$

CAPÍTULO 6 .65

OFICINAS DE CORDEL COM TEMAS DE BIOLOGIA

Edmilson Clarindo de Siqueira

José Adonias Alves de França

Silvana Caroline de Holanda

DOI: $10.47094 / 978-65-88958-18-6 / 65-75$

CAPÍTULO 7.

RELAÇÃO HOMEM E NATUREZA NAS MARGENS DO RIO PERICUMÃ NA CIDADE DE PINHEIRO-MA

Gabrielly Soares Dias Gonçalves 
Jenilce Monica Ferreira Fernandes

Werberth Braga Bastos

Hellen José Daiane Alves Reis

DOI: $10.47094 / 978-65-88958-18-6 / 76-86$

CAPÍTULO 8 .87

METODOLOGIAS ATIVAS NO ENSINO DE FISIOLOGIAHUMANA: O OLHAR DOS FUTUROS PROFESSORES

Maria Iracema Barbosa Moura

Francisco de Assis Pereira da Silva

Helayne Barbosa Moura

DOI: 10.47094/978-65-88958-18-6/87-96

CAPÍTULO 9 97

CORRIDA DE ESPERMATOZOIDES: SEXO E HERANÇA - UMA PROPOSTA INTERATIVA PARA O ENSINO DE HEREDITARIEDADE

Fernanda Pacheco-Fernandes

Benn Richard Alle

Iris Hass

Luciane Viater Turek

Maíra Alexandre Peres

Lupe Furtado-Alle

DOI: $10.47094 / 978-65-88958-18-6 / 97-112$

CAPÍTULO 10 113

DANÇA DOS CROMOSSOMOS: USANDO A LUDICIDADE PARA ENSINAR HEREDITARIEDADE 
Fernanda Pacheco-Fernandes

Benn Richard Alle

Iris Hass

Luciane Viater Tureck

Maíra Alexandre Peres

Lupe Furtado-Alle

DOI: $10.47094 / 978-65-88958-18-6 / 113-126$

CAPÍTULO 1

A DiscuSSÃO DA HOMOSSEXUALIDADE EM UM LIVRO PARADIDÁTICO DE SEXUALIDADE

Lucas Mendes Silva

Vitoria Raquel Pereira de Souza

Jackson Ronie Sá-Silva

DOI: $10.47094 / 978-65-88958-18-6 / 127-137$ 


\title{
RELAÇÃO HOMEM E NATUREZA NAS MARGENS DO RIO PERICUMÃ NA CIDADE DE PINHEIRO-MA
}

\section{Gabrielly Soares Dias Gonçalves ${ }^{1}$}

Universidade Federal do Maranhão (UFMA), Pinheiro, Maranhão

http://lattes.cnpq.br/2195430516463814

Jenilce Monica Ferreira Fernandes ${ }^{2}$

Universidade Federal do Maranhão (UFMA), Pinheiro, Maranhão

http://lattes.cnpq.br/5812766861185745

\author{
Werberth Braga Bastos ${ }^{3}$ \\ Universidade Federal do Maranhão (UFMA), Pinheiro, Maranhão \\ http://lattes.cnpq.br/1797054816522191
}

Hellen José Daiane Alves Reis ${ }^{4}$

http://lattes.cnpq.br/8603879841510002

RESUMO: Desde os primórdios é notável a relação entre homem e natureza, assim como sua dependência para própria subsistência, ressalta-se que essa subsistência em grande parte vem da caça e pesca, as quais o homem primitivo aprendeu a dominar, alimentando- se de animais vertebrados que eram fontes de proteínas para si e sua comunidade. Nesse sentido, o objetivo deste artigo é descrever as relações existentes, entre o homem, natureza e os animais vertebrados, assim como sua importância. A metodologia qualitativa na modalidade de observação in loco foi utilizada para descrever essa conexão entre homem e natureza/vertebrados. Os autores utilizam parâmetros préestabelecidos para essa observação elencados em um diário de bordo; por um período de cinco dias, em horários diversos onde foram realizadas essas observações, nelas eram feitas as considerações necessárias para posterior discussão. Os itens observados incluíam os animais vertebrados e o ser humano. No decorrer das observações foi possível detectar a pesca de subsistência na região, ressaltase que na área estudada os pescadores nativos dependem diretamente dessa relação ecossistêmica para sua sobrevivência e consequentemente da sua família. Após as análises e ponderações acerca dessa relação reafirmamos a existência dessa interligação do homem a esse ambiente que dá condições para sua subsistência. Destaca-se neste artigo que além de uma consciência biológica, toda população precisa adquirir responsabilidade com o ambiente qual estão inseridos, já que em vários locais o lixo é 
perceptível, prejudicando não só os animais nativos da região como também as pessoas que dependem diretamente desse local. São mudanças necessárias para toda uma biosfera que pode e vem sendo prejudicada pelos avanços demasiados da espécie humana.

PALAVRAS-CHAVE: Homem. Natureza. Relação.

\title{
MAN AND NATURE RELATIONSHIP ON THE PERICUMÃ RIVER RIVER IN THE CITY OF PINHEIRO-MA
}

\begin{abstract}
Since the beginning, the relationship between man and nature is remarkable, as well as his dependence for his own subsistence, it is emphasized that this subsistence largely comes from hunting and fishing, which the primitive man learned to dominate, feeding on vertebrate animals that were sources of protein for you and your community. In this sense, the purpose of this article is to describe the existing relationships between man, nature and vertebrate animals, as well as their importance. The qualitative methodology in the modality of on-site observation was used to describe this connection between man and nature / vertebrates. The authors use pre-established parameters for this observation, listed in a logbook; for a period of five days, at different times where these observations were made, the necessary considerations were made for further discussion. Observed items included vertebrate animals and humans. During the observations, it was possible to detect subsistence fishing in the region, it should be noted that in the studied area, native fishermen depend directly on this ecosystem relationship for their survival and, consequently, on their family. After analyzing and considering this relationship, we reaffirm the existence of this interconnection of man to this environment that gives conditions for his subsistence. It is noteworthy in this article that in addition to a biological awareness, the entire population needs to acquire responsibility for the environment in which they are inserted, since in several places the garbage isnoticeable, harming not only the animals native to the region but also the people who depend directly on this place. These are necessary changes for an entire biosphere that can and has been hindered by too many advances in the human species.
\end{abstract}

KEY WORDS: Man. Nature. Relationship.

\section{INTRODUÇÃO}

Desde os primórdios é notável a relação entre homem e natureza, assim como sua dependência para própria subsistência, e grande parte esse vínculo vem da caça e pesca, as quais o homem primitivo aprendeu a dominar, alimentando-se de animais vertebrados que eram fontes de proteínas para si e sua comunidade. Ao longo dos anos o homem criou inúmeras relações com os animais, tirando deles não só a alimentação, mas a força, agilidade, tamanho, couro, dentição etc., entretanto nem sempre essa relação é benéfica para ambos os lados, em diversas ocasiões o meio ambiente fica em desvantagem 
No planeta Terra há uma diversidade de biomas e seres vivos, como florestas, lagos, campinas, desertos, pântanos, oceanos e muitos outros habitats que abrigam uma variedade de seres vivos, vertebrados e invertebrados dos quais o homem sempre obteve e obtém algum benefício. Há também bactérias, fungos, vírus e protozoários relevantes no processo de decomposição das matérias, limpando o planeta e ciclando nutrientes. Às vezes, parece até que cada ser vivo vive de forma isolada, sem influenciar ou ser influenciado por outros. Contudo, a natureza mantém uma íntima interdependência entre os seres vivos, ligando o Reino Monera, Reino Protista, Reino Fungi, Reino Plantae, Reino Animalia e o meio ambiente como um todo, que mantém e sustenta toda essa infinidade de vida na Terra (ALBUQUERQUE, 2007).

Entretanto, essas dependências mútuas necessitam ser pautadas em ações de preservação e manutenção da biodiversidade e vida existente, promovendo ações que não causem prejuízos ao meio ambiente, mas possibilite a ele e aos seres vivos imersos nele uma vivência não comprometida pelas ações antrópicas. Diante de todos os argumentos citados, o que este trabalho propõe como objetivo é averiguar justamente essa relação homem e meio ambiente na qual toda a história humana está pautada, bem como a importância dos animais vertebrados para esse meio, focando em uma região importantíssima para sobrevivência de uma comunidade: as margens do Rio Pericumã, na cidade de Pinheiro, no estado do Maranhão.

\section{METODOLOGIA}

O presente estudo foi realizado as margens do Rio Pericumã, na cidade de Pinheiro, Maranhão, com $115 \mathrm{~km}$ de extensão, o Rio Pericumã abastece cerca de $85 \%$ da população pinheirense, além de fornecer água para cidade ainda fornece para 16 sistemas distribuídos em várias localidades. A cidade de Pinheiro, se localiza entre a porção noroeste do estado do Maranhão, possuindo uma bacia que se estende entre os paralelos $2^{\circ} 02^{\prime}$ a $3^{\circ} 07^{\prime}$ de latitude Sul e nos meridianos $44^{\circ} 30^{\prime}$ a $45^{\circ} 30^{\prime}$, localização a oeste de Greenwich, drenando uma área por volta de $3.888,55 \mathrm{~km}^{2}$, correspondendo cerca de $1,17 \%$ de todo território maranhense. Sobre a rede hidrográfica, a mesma possui preponderâncias de padrão dentrítico, constituída de rios em geral intermitentes ou rios de chuva, já que só apresentam cauda durante a ocorrência dos eventos pluviométricos na região (BERNARDI, 2005).

Nessa região temos a abundância de água, no fundo dos lagos há grande quantidade de matéria orgânica proporcionando o crescimento e desenvolvimento saudável dos cardumes da região, possibilitando uma grande abundância de peixes no período em que o nível do rio começa a baixar. Nesses ambientes de baixas, existem locais mais profundos, onde esses cardumes variados ficam confinados, tornando-se presas fáceis para pescadores que se beneficiam desse evento (LAFONTAINE, LAFONTAINE, 2009). O curso de água em particular sofre influência de marés, por essa questão existe uma Comporta que realiza a barragem da água salgada para água doce, trabalho esse realizado e monitorado pela Companhia de Saneamento Ambiental do Maranhão (CAEMA). Caso 
não houvesse essa separação teríamos um desastre ambiental já que vários agricultores familiares, pequenos produtores de animais e pescadores nativos serem atingidos em cheio com tal mistura de águas (CAEMA, 2006).

A Baixada Maranhense, onde se localiza a cidade de Pinheiro possui uma população rural superior à população urbana de acordo com o IBGE. Esse fato corrobora com o grande quantitativo da população que direta ou indiretamente está vinculada a atividades derivadas da produtividade rural. Essas atividades, por sua vez assumem papel importante na área socioeconômica da cidade de Pinheiro, porém essa atribuição também contribui para o surgimento de inúmeros problemas de ordem ambiental, algo não obstante a outras realidades. Assim as atividades principais que são desenvolvidas na zona rural da região são a pesca para subsistência e venda, assim como a agricultura familiar, a pecuária e o extrativismo (MARANHÃO, 2006). É visível que essas atividades possuem um vínculo estreito com o ecossistema de várzea os considerados campos inundáveis, possibilitando uma dinâmica típica as várias comunidades rurais da região (LAFONTAINE, LAFONTAINE, 2009).

O flume faz parte da história da cidade, nele há sobrevivência de milhares de famílias baixadeiras que vivem da pesca, criação de animais e outras atividades essenciais para sobrevivência das mesmas. Nas margens do Rio é comum a venda de peixe da água doce, venda de animais, farinha típica da região, comidas, pessoas contemplando o rio, fazendo exercícios, etc., provando a relação intrínseca dos pinheirenses com esse local (MARANHÃO, 2006).

A pesquisa em questão é caracterizada qualitativamente por ser um estudo que busca captar determinados grupos sociais, organizações, ciclos de vivências etc., além de ser entendido como uma forma de pesquisar e obter dados sobre um objeto de estudo (GOLDENBERG, 1997). Com relação à pesquisa qualitativa Deslauriers (1991) esclarece que o pesquisador é ao mesmo tempo o sujeito e o objeto de suas pesquisas, o que se revela interessantíssimo no que diz respeito a pesquisa científica. Assim, a evolução da pesquisa é essencial, os pesquisadores tem conhecimentos que precisam ser parciais e auxiliarão na busca do objetivo central da amostra que tem como finalidade produzir informações, noções e dados que possam ser otimizados e ilustrativos, mesmo que sejam pequenos ou grandes, o que importa é que tenha capacidade de produzir novos horizontes para a pesquisa (DESLAURIERS, 1991).

Para coleta de dados foram realizadas observações e anotações em registros cursivos (contínuo), uso de palavras-chaves, check list e códigos, transcritos posteriormente (DANNA; MATOS, 2006). A observação é definida por Barton e Ascione (1984) como um processo de várias partes: o objeto observado, o sujeito, as condições, os meios e o sistema de conhecimentos, e a partir destes se formula o objetivo da observação. Para tanto vale ressaltar que as condições para uma observação são esporádicas, ou seja, é o contexto natural ou artificial no qual o fenômeno se manifesta ou se reproduz, a partir daí a observação é realizada, tendo como foco o objetivo da investigação. Por sua vez, o sistema de conhecimento, determina o corpo de conceitos, as categorias e os fundamentos teóricos que embasam a pesquisa, ou seja, o olhar do pesquisador deve ser apurado para qualquer evento pertinente a ser descrito (REYNA, 1997). 
Assim utilizamos para esta pesquisa observações em dias distintos da semana, totalizando cinco dias de análises nas margens do Rio Pericumã no mês de maio do ano de 2019. Em possa de uma tabela pré-estabelecida, anotou-se os dados necessários como nome dos animais, quantidade, local encontrado e horário, assim poderíamos saber que tipo de interação estava ocorrendo no local e trazer posterior discussão. As observações foram bem simples, em menos de meia hora já era possível obter resultados significativos para traçar um panorama sobre a relação homem natureza/vertebrados. Após as observações, seguimos com as discussões sobre a temática proposta.

\section{RESULTADOS E DISCUSSÕES}

A partir das observações foi possível detectar a pesca de subsistência na região, destacando que a área estudada possui pescadores nativos que dependem diretamente dessa relação ecossistêmica para sua sobrevivência e, consequentemente, da sua família. Algo importante de ser observado, já que a presença humana dentro, às margens e próximas ao Rio Pericumã é constante, a interação com os animais nativos da região, a pesca de subsistência, as vendas dos peixes por atravessadores movimentam não só aquela área mais toda uma cidade que depende do alimento retirado do Rio para sua população. Nesse sentido, reafirma-se as características da pesca em ambientes lacustres da Baixada e como fazem parte expressiva dos habitantes dos municípios dessa Microrregião se dedicam à pesca ou a alguma atividade que tenha relação direta com os lagos (MARANHÃO, 2006).

Em função disso, a pesca assume relevância social e econômica no contexto regional, pois, além de suprir parte do alimento que compõe a dieta da população diretamente envolvida, ainda é uma das atividades que gera grande parte da renda e importantes postos de trabalho nas comunidades rurais de todos os municípios que compõem a aludida Microrregião (GUTMAN, 2005). Nesse sentido, a pesca na região se dá principalmente pela captura das espécies como piabas (Moenkhausia sanctaefilomenae), bagre (Siluriformes) e traíra (Hoplias), todas encontradas junto aos pescadores nas margens do rio com quantidade significativa desses peixes repassadas A atravessadores, que posteriormente fazem a venda da pesca nas feiras da cidade, gerando renda e alimentação para as famílias dos pescadores.

Foram encontradas diversas espécies interagindo as margens do Rio Pericumã, entre elas pássaros como andorinha (Hirundinidae), socó (Tigrisoma lineatum), curió (Oryzoborus angolensis), jaçanã (Jacana jacana), rolinha (Columbina), bem-te-vi (Pitangus sulphuratus), sangue de boi (Ramphocelus bresilius), graúna (Molothrus oryzivorus).

As aves, além de serem animais que possuem certa beleza, segundo Andrade (1997) são importantes para a vida humana e a natureza por auxiliarem no controle de insetos e de populações de ratos e cobras, e na coleta do lixo e de animais mortos. São fundamentais na polinização, na disseminação de sementes e como alimento, são fontes de inspiração para música, poemas, fotografias e transmitem sensação de bem estar. Muitas destas funções das aves passam despercebidas e não é dado o valor adequado a esses animais, que muitas vezes são mortos apenas por diversão, podendo 
prejudicar todo um ecossistema, um exemplo dessa realidade é a venda ilegal de exemplares na margens do Rio, em que foram encontradas diversas gaiolas com aves aprisionadas e postas à venda, causando um prejuízo natural irreparável.

As aves desempenham papel considerável na disseminação da educação ambiental, justamente por estimularem as pessoas a preservação, seu colorido, os arranjos da plumagem, tamanho e anatomia do corpo, capacidade de voo, vocalização, aparência dócil e demais características chama atenção das pessoas (SILVA; MAMEDE, 2005). Argel-de-Oliveira (1997) inferi que as aves não provocam repulsa nas pessoas, mas geralmente esse sentimento é voltado aos outros vertebrados, como ratos, morcegos, ratos, répteis e anfíbios, geralmente as pessoas não mantem proximidade com animais silvestres, justamente por representarem perigo a espécie.

Assim, preservar essas espécies observadas e as demais que vivem na região da Baixada Maranhense como um todo é essencial não só para o equilíbrio ecológico do local, mas para conservação dessas espécies nativas e migratórias que tem o Rio Pericumã como fonte inesgotável de alimentos, suas margens como moradia e repouso, e suas águas como fonte de nutrição.

Desta forma, levar o entendimento da importância da conservação das aves e consequentemente de outros animais e de todo um ecossistema é algo que precisa ser trabalhado e pensado por todos os órgãos responsáveis pela segurança desses animais. Padua et al. (2003) ressalta que para uma possível conservação e preservação desses animais seria necessária uma adoção a partir de abordagens participativas que permitam a população e as regiões próximas a áreas naturais um envolvimento efetivo, e consequentemente a promoção dessa prevenção. Já Feisinger (2004) enfatiza que na prática da conservação tanto do ambiente como da biodiversidade como um todo, parte de um esforço coletivo, não somente dos profissionais especializados, mas principalmente da colaboração das comunidades locais que são parte integrante de todo esse hábitat.

Entre os mamíferos, observamos gatos (Felis catus) e cachorros (Canis lupus familiaris) trazidos pelos pescadores, atravessadores e consumidores dos peixes vendidos nas margens, em sua maioria, domesticados e alguns vivendo em condições de rua. Observou-se também exemplares de cavalos (Equus caballus) e jumentos (Equus asinus) que interagem nas margens pastando e consumindo a vegetação nativa da região, deslocados pelos seus proprietários para várias áreas ao longo da extensão do rio. Além disso, encontramos o búfalo (Bubalus arnee), animal introduzido na região há alguns anos e que hoje muda a paisagem do campo, com grande número de indivíduos dessa espécie pastando a beira do Rio, animais esses que possuem hábitos mais oportunistas e dietas amplas e flexíveis, podendo, até certo limite, ajustar-se a ambientes antropizados, sendo considerados mais tolerantes às modificações no habitat, adaptando-se muito bem ao clima e alimentação da região (UMETSU; PARDIN, 2007).

Porém, mesmo com uma extensão territorial grandiosa, os mamíferos dessa região sofrem com a perda e a fragmentação de habitat, resultantes de atividades humanas que constituem as maiores ameaças aos mamíferos terrestres no Brasil como um todo. Essas ações estão relacionadas ao desenvolvimento econômico através do crescimento de áreas cultivadas, ocasionado grande 
número de queimadas e a invasão urbana, que nas margens do rio se caracteriza por inúmeras palafitas, aterramentos de áreas de proteção ambiental, casas e mais casas sendo construídas a beira das águas do Pericumã, invadindo sem a mínima consciência de conservação do campo da cidade.

Além dos impactos citados, ainda temos a poluição atmosférica e aquática, essa registrada pela grande quantidade de lixo jogado indiscriminadamente no Rio atingindo diretamente os animais que sobrevivem nessa região (COSTA et al., 2005). Nota-se que o impacto das atividades humanas sobre a fauna silvestre depende da intensidade e da natureza dessas atividades e da espécie em questão. Porém, independentemente das causas, as alterações ambientais afetam a biodiversidade como um todo, os processos ecológicos importantes e também aumentam as chances de instabilidade nesse habitat, causando sérios danos naturais de ordem coletiva, já que o homem está inserido na natureza e receberá o fruto de suas ações sobre a mesma.

Entre os mamíferos ainda podemos destacar a presença do homem (Homo sapiens), presença essa notória em quase todas as observações, fator que só ressalta o citado na introdução: “As principais atividades desenvolvidas na zona rural da Baixada são a pesca, a agricultura, pecuária e extrativismo (MARANHÃO, 2006) e essas atividades apresentam um vínculo estreito com o ecossistema de várzea (campos inundáveis), dando uma dinâmica típica às várias comunidades rurais da região" (LAFONTAINE; LAFONTAINE, 2009, p.97).

Nas observações de exemplares de peixes, os pescadores nativos tiveram presença assídua, identificando as espécies e trazendo relatos de suas pescarias, observamos também a presença de pequenos produtores de animais, atravessadores e consumidores de carnes que no início da manhã se reúnem nas margens do rio para compra de alimentos frescos vindos da pesca e captura de animais, evidenciando uma relação homem e natureza estabelecida tempos atrás. É interessante ressaltar que muitos tiram dessas atividades sua subsistência, porém poucos tem conhecimento acerca da manutenção e preservação daquilo que tem sido suas fontes de renda e alimento.

No grupo dos répteis encontramos lagartos (Lacertilia) expondo-se ao sol para permitir o aumento da atividade corpórea derivada da ação da temperatura no corpo desses animais, essa tendência era relatada no século passado pela literatura da época (BOGERT, 1959). Um exemplo bem comum são os lagartos que no curso de sua rotina ao longo do dia dependem uma grande parte do conjunto de fontes de calor do ambiente, como por exemplo a irradiação solar, ao calor do ar, e também dos substratos onde estão inseridos (KIEFER et al., 2005).

Ademais, cada espécie de lagarto utiliza essa "energia" derivadas de certas fontes de calor em maior ou menor grau, de acordo com sua termorregulação, porém essa temperatura em atividade reflete a interação entre fontes distintas de calor, do que de uma única fonte (HUEY; SLATKIN, 1976). Em relação ao comportamento, essa regulação inferi no deslocamento para locais mais frescos (sombreados) e mais quentes (insolados), isso explica por que encontramos os lagartos durante a manhã e, geralmente, expostos ao calor intenso do sol.

No meio dos anfíbios, os sapos (Anura) e rãs (Ranidae) também estavam com exemplares 
presentes no local. Os anfíbios podem ser caracterizados por serem organismos importantíssimos para o fluxo energético, sendo estimado que transformam aproximadamente $90 \%$ do que ingerem, evidenciando as taxas de desenvolvimento elevadíssimas, contribuindo para o equilíbrio do ecossistema tendo função de reguladores dos insetos e demais invertebrados, ainda contribuem sendo alimento na cadeia alimentar para grupos de répteis, aves e mamíferos (BASTOS et al., 2003; WOEHL, 2007).

Os anuros, por sua vez ocupam inúmeros microambientes, como a alagados, matas, estratos verticais onde utilizam para forrageamento e reprodução, explicando sua disseminação nas margens do Rio Pericumã (HADDAD et al., 2013), onde possui grande disponibilidade de água e umidade, ambiente ideal para propagação dessas espécies. Porém, toda e qualquer alteração nesses ambientes resulta em algum impacto e consequentemente no declínios populacional desses animais, promovendo inclusive a extinções em determinados locais, além de causar um desequilíbrio, já que exercem funções vitais para a harmônia do ambiente (FEDER; BURGGREN, 1992).

Das várias características primordiais anfíbios podemos citar ainda alguns aspectos biológicos e ecológicos, como depender diretamente de ambientes aquáticos ou úmidos para sua reprodução; a pele úmida permeável, exposta; baixa habilidade de locomoção e sensibilidade as mudanças no ambiente (HADDAD; PRADO, 2005), expondo esses animais a subsistência de ambientes aquosos e úmidos. Além disso são excelentes indicadores de qualidade ambiental, possibilitando a identificação quanto a preservação dos seus habitats e as mudanças climáticas que aceleram a perda de espécies raras e endêmicas dessa e de outras regiões (KIESECKER; BLAUSTEIN; BELDEN, 2001).

Atualmente a principal ameaça para conservação dos anfíbios é justamente a destruição de seus habitats, consequência do desmatamento, mineração, das queimadas, do avanço das fronteiras agrícolas, além do desenvolvimento da infraestrutura e urbanização nos habitats desses animais. No Brasil, pouco se sabe a respeito das múltiplas causas de declínio dos anfíbios monitorados mundialmente, como os efeitos dos pesticidas nas lavouras, mudanças climáticas, espécies invasoras ou comércio de animais silvestres, doenças infecciosas etc., (BOGDAN, 1994).

No que diz respeito aos invertebrados, os insetos (Insecta) estão em grande quantidade nas margens do rio Pericumã, sendo parte integrante daquele local. Os insetos representam uma grande cadeia de sobrevivência de animais vertebrados, possuem relação estrita com o ser humano. Possuem a capacidade de sobreviver e se alimentar nos mais diversos ambientes, se adaptando facilmente em madeiras, plantas, néctar e até sangue. Dependendo da espécie, podem ser benéficos ou maléficos. São alimento para aves, répteis, anfíbios, mamíferos e peixes, todos observados nessa pesquisa. Caso fossem eliminados por completo de uma área, o desequilíbrio ecológico seria gigantesco, já que afetaria uma grande quantidade de seres vivos. Um exemplo são as borboletas e as abelhas, responsáveis pela reprodução de algumas plantas através do transporte de pólen, sendo agentes polinizadores garantindo a fecundação de vários vegetais (EMBRAPA, 2020).

Dentre a vegetação encontrada, a predominante foi a conhecida popularmente como aguapé (Eichhornia crassipes) presente em grande parte do rio, ela serve de habitat para piranhas jovens, alevinos, insetos e outros organismos aquáticos. É importante alimento para coelhos, galinhas, 
burros, ovelhas e cabras. Sua abundância é devida a sua semente que é liberada na água e pode sobreviver 15 anos submersa(PINHEIRO, 2013).

Os igapós em geral estão localizados na parte inundável das margens de lagos, rios e canais, sua tipologia de vegetação é caracterizada como mata de igapó. Esse tipo de vegetação é muito frequente na região, principalmente nas margens de lagos. Sofrem influência anual do nível das águas sujeitas a inundação durante períodos de até 6 meses anuais, contribuindo para selecionar espécies de plantas e animais adaptadas à inundações (RODRIGUES, 2000; RODRIGUES \& GANDOLFI, 2001). A própria população da Baixada observa as modificações existentes e principalmente exercidas pela ação humana no decorrer das últimas três décadas, derivadas, queimadas, barramentos de igarapés, desmatamentos, entre outros problemas. Observamos atualidade que a vegetação vem sendo modificada, tornando-se pouco diversa, com dominância de poucas espécies mais tolerantes a períodos mais longos de seca, bem como a outras condições modificadas no ambiente regional. Assim é extremamente necessário, estudos relacionados aos efeitos das modificações sobre a vegetação da região (PINHEIRO, 2013).

Além de tudo isso, observou-se uma grande quantidade de lixo as margens do rio, desde garrafas de vidro a latinhas de cerveja, como também uma carcaça de geladeira, material esse que enferruja na água liberando puro ferro, foram observados muitos plástico em quase toda a extensão observada, fator que causa impactos na vida de muitas espécies, principalmente aos peixes que facilmente confundem o plástico com comida e ingerem esse alimento, consequentemente morrerem ou entram nas casas dos consumidores locais contaminados, esses impactos a curto e longo prazo podem causar um enorme prejuízo nesse ecossistema e degradar um espaço que abriga milhares de seres vivos dependentes diretos desse ecossistema.

\section{CONSIDERAÇÕES FINAIS}

Após as análises e ponderações acerca da relação homem e natureza podemos concluir que há uma dependência direta do homem a esse ambiente que dá condições para sua subsistência, assim como a relação direta de cada ser vivo que compreende as margens do rio Pericumã, cada um exercendo funções primordiais para o equilíbrio desse hábitat. Destaca-se ainda neste artigo que além de uma consciência biológica, toda população precisa adquirir responsabilidade com o ambiente que estão inseridos, já que em vários locais o lixo era perceptível, prejudicando não só os animais nativos da região mais também as pessoas que dependem diretamente desse local. Mudanças são necessárias, exercendo caráter preventivo por parte da população no que diz respeito a preservação de um ambiente que todos direta ou indiretamente dependem. O rio Pericumã em geral é um ambiente rico, cheio de vida como relatado neste artigo e precisa da conservação de todos para que as futuras gerações também possam se beneficiar com as aguas salutares desse ecossistema que carrega em suas águas a história de uma cidade, de pescadores, famílias e mais famílias que dependem desse bem. 


\section{REFERÊNCIAS}

ANDRADE, M. A. Aves silvestres: Minas Gerais. Belo Horizonte: Líttera Maciel. 1997. 176 p.

ALBUQUERQUE, Bruno Pinto de; OLIVEIRA, Alfredo César Tavares de; REIS, José Roberto Franco. As Relações Entre O Homem E A Natureza E A Crise Sócio-Ambiental. 2007. 93p. TCC (Graduação) - Curso de Biologia, Escola Politécnica de Saúde Joaquim Venâncio da Fiocruz, Rio de Janeiro, 2007.

ARGEL-DE-OLIVEIRA, M. M. 1997. El uso de aves en Educación Ambiental. Encuentro Boliviano para la Conservación de las Aves, Santa Cruz de la Sierra,. Actas. Santa Cruz de la Sierra, Armonía, BirdLife International, v. 3, p. 27-30

BASTOS et al. Anfíbios da Floresta Nacional de Silvânia, Estado de Goiás. Goiânia: Universidade Federal de Goiás, 2003.

BERNARDI, Cristina Costa. Conflitos Sócio-Ambientais Decorrentes Da Bubalino cultura Em Territórios Pesqueiros Artesanais: o caso de Nova Olinda do Maranhão. (Dissertação de Mestrado). Brasília: Universidade Católica de Brasília, p.92, 2005.

BOGDAN, R.; BIKLEN, S. Investigação Qualitativa em Educação. Porto, Portugal: Porto Editora, 1994.

BOGERT, C. M. How reptiles regulate their body temperature. Scientific American, 200: p. 105$120,1959$.

CAEMA. Abastecimento e Tratamento de Água no Município de Pinheiro-MA. Entrevista cedida a Lílian Vieira Alves, 2006.

COSTA, L. P.; LEITE, Y. L. R.; MENDES, S. L.; DITCHFIELD, A. D. Mammal

conservation in Brazil. Conservation Biology, v. 19, n. 3, p. 672-679,2005.

DESLAURIERS, J. P. Recherche Qualitative. Montreal: McGraw Hill, 1991.

EMBRAPA. Programa Embrapa \& Escola para 2020 tem novidade - a importância dos insetos. São Paulo, 05 abr. 2020. Disponível em: <https://www.embrapa.br/busca- de-noticias/-/ noticia/50645767/programa-embrapa--escola-para-2020-tem-novidade--a- importancia-dosinsetos>. Acesso em: 12 nov. 2020.

FEDER, M. E.; BURGGREN,W. W. Environmental physiology of the amphibians. Chicago and London: The university of Chicago press. p.125-150. 1992.

FEINSINGER, P. 2004. EI Diseño de Estudios de Campo para la Conservación de la Biodiversidad. Santa Cruz de la Sierra, Editoral FAN (Fundación Amigos de la Naturaleza) Bolivia.

GOLDENBERG, M. A arte de pesquisar. Rio de Janeiro: Record, 1997. Disponível em: 
$<$ https://www.researchgate.net/publication/307668580_O_solo_no_ensino_de_ciencias

_no_nivel_fundamental/citation/download >. Acesso em: 02 out. 2020.

GUTMAN, S. M. Caracterização Do Sistema De Produção Lavrador-Pescador Em Comunidades Rurais No Entorno Do Lago De Viana, Na Baixada Maranhense. (Dissertação de mestrado). São Luís, MA: UEMA, 2005.

HADDAD, C. F. B.; PRADO, C. P. A. Reproductive Modes in Frogs and Their Unexpected Diversity in the Atlantic Forest of Brazil. BioScience, Oxford-Inglaterra, v. 55, n. 3, p. 207-217, 2005.

HADDAD, C. F. B.; TOLEDO, L. T.; PRADO, C. R. A.; LOEBMANN,

D.;GASPARINI, J. L. Guia de Anfíbios da Mata Atlântica: Diversidade e Biologia. Anolis Books, São Paulo. 544 p. 2013.

HUEY e SLATKIN, 1976; KOHLSDORF, T. e NAVAS, C. A. 2006. Ecological constraints on the evolutionary association between field and preferred temperatures in tropidurinae lizards. Evolutionary Ecolog, v. 20: p. 549-564.

KIEFER, M. C.; VAN SLUYS, M. e ROCHA, C. F. D. thermoregulatory behaviour in Tropidurus torquatus (squamata, tropiduridae) from Brazilian coastal populations: an estimate of passive and active thermoregulation in lizards. Acta Zoologica, v. 88, p. 81-87, 2007.

LAFONTAINE, Luís Carlos; LAFONTAINE, Teresa Cristina. As Relações Entre O Homem E A Natureza E A Crise Sócio-Ambiental: Uma Beleza Ameaçada Pela Dinâmica Das Comunidades Rurais. In: Jornada Internacional De Políticas Públicas, 4., 2009, São Luís. Anais. São Luís: SBPP, p. $1-5,2009$.

MARANHÃO. Ministério Público Estadual. Mpe Discute Proteção Aos Campos Inundáveis Da Baixada Maranhense. Disponível em <http://www.pgj.ma.gov.br/>. Acesso em 20 de set de 2020.

PINHEIRO, C. U. B. 2013. Matas Ciliares: Recuperação e Conservação em Áreas Úmidas do Maranhão. Editora Aquarela, São Luis-MA.

PADUA, S. M., TABANEZ, M. F. e SOUZA, M. G. A abordagem participativa na educação para a conservação da natureza, em: Métodos de Estudo em Biologia da Conservação e da Vida Silvestre (L Cullen-Jr, R Rudran e CV Pádua, orgs.). Curitiba: Editora UFPR (Universidade Federal do Paraná), p. 557-591, 2003.

SILVA, M. B. e MAMEDE, S. B. Grupos de observadores de aves e mamíferos como estratégia para a conservação da biodiversidade do Cerrado. p. 55-58, 2005.

UMETSU, F. \& PARDINI, R. Small mammals in a mosaic of forest remnants and anthropogenic habitats evaluating matrix quality in an Atlantic forest landscape.

Landscape Ecol. v. 22, p. 517-530, 2007. 


\section{ÍNDICE REMISSIVO}

\section{Símbolos}

$1^{\mathrm{a}}$ e $2^{\mathrm{a}}$ Lei de Mendel 114,116

A

alelos 98, 99, 100, 101, 102, 105, 107, 108, 110, 117, 118, 119, 121, 122, 123, 124

alfabetização científica 42, 44, 51, 61, 62

alginato $42,44,45,46,48,52,53,55,56,57,59,64$

alginato de sódio 42, 44, 45, 46, 53, 56, 57

ambiente escolar $13,29,53,55,58,89$

animais nativos $76,80,84$

animais vertebrados $76,77,78,83$

animais vertebrados e o ser humano 76

Aprendizagem 18, 65, 67, 112

aprendizagem de biologia 114

atividade experimental $44,45,46,53,55,56,58,62$

atividades remotas 11,15

aulas de biologia 28

aulas presenciais $11,15,17,89,90$

aulas remotas 11,13

a vida em sociedade 127

B

Biologia $6,11,14,15,16,17,20,22,24,26,27,37,40,41,63,85,86,88,100,110,112,115,116,124,125,133$

biologia celular 114,115

botânica 65,70

C

campo da ecologia 65,69

campo da nanotecnologia 53,62

caráter histórico e dinâmico da ciência $\square 28,36,37$

carreadores de fármacos $42,43,44$

cátions bivalentes 53,55

ciclo da doença $20,22,23$

ciência como atividade coletiva $\square 28,36,37,38$

Ciências $11,12,14,15,16,18,22,24,26,40,41,43,44,48,50,62,65,67,75,87,91,110,111,112,117,125,137$ 
citologia $37,65,70$

compreensão e fixação das informações 19

comunidade $20,22,25,76,77,78$

conceito de homofobia 127,134

concentração nos estudos 11, 15

conexão de internet 11

conhecimentos da genética 114

consciência biológica 76, 84

construção de cordéis 65,67

conteúdo didático 11,12

conteúdo informativo 20

cromossomos $98,99,100,101,102,104,105,106,108,109,110,114,115,117,118,119,120,121,122,123,124$

$\mathbf{D}$

Dança dos Cromossomos 114, 116

déficit informativo 19

didáticas alternativas 98

dificuldade de entender os conceitos 11

dificuldade na compreensão 97

Dificuldades de aprendizagem 11, 111, 125

dificuldades do aprendizado 11

dinâmica das aulas 87,88

disciplina de genética 97, 115

dispositivo eletrônico 11, 16

disseminação de conhecimento 20, 21

diversidade $71,77,127,132$

doenças negligenciadas 19

dominância completa 98, 100

E

Educação básica 11

educação sexual 127,135

Enfrentamento das visões ingênuas sobre a ciência 28

ensino da hereditariedade 97

ensino de ciências $27,28,32,40,42,51,96,125$ 
ensino de parasitologia 19,22

ensino remoto $11,13,14,17,87,88,89,90,91,92,96$

entendimento sobre a amebíase 20

esferas de alginato $42,45,46,47,48,53,56,57,58,59,60$

espécie humana 77, 101

espermatozoides 98, 100, 102, 107, 108, 109

Estratégias 26, 63, 65

estudantes de biologia 98

Estudos Culturais em Educação 127, 128

estudos histórico-filosóficos 28

etapa experimental 53

F

falta de reflexão sobre a $\mathrm{NdC} 28$

família 76, 80, 136

farmacocinética 42,50

fármacos $42,50,55$

fechamento das escolas 11,12

fenômeno biológico 101, 108, 113, 115

fenômenos biológicos 114

fenótipo 98, 100, 103, 108, 124

ferramenta didática $65,67,114$

ferramenta didática adjuvante 65

fisiologia humana 87, 91, 94

formação dos gametas 114, 117, 118, 119, 121, 124

formato de aprendizagem 11

formulação convencional 42

fusos meióticos 114, 120, 122

G

genótipo 98, 100, 101, 102, 124

graduação nas áreas biológicas 98

H

hereditariedade $98,99,101,110,111,112,113,114,115,125,133$

homem e natureza $76,77,82,84$ 
homem e natureza/vertebrados 76

homem primitivo 76,77

homossexualidade 127, 128, 129, 130, 131, 132, 133, 134, 135, 136, 137

I

Inclusão 11

inteligência cinestésico-corporal 114, 116

interdisciplinaridade 42,50

interesse em aprender 87, 95

J

jovens em idade escolar 11

$\mathbf{L}$

Leis de Mendel 110, 113, 114, 115, 125

Ligação Gênica 114, 116, 121, 123, 125

linguagem e conceitos complexos 19,21

lipossomas 42,44

Literatura $65,74,75$

literatura de cordel $65,66,67,68,73,74,75$

livro paradidático de sexualidade 127, 128, 129, 131, 132

livros didáticos $28,31,32,33,34,35,36,38,39,41,48$

livros didáticos de biologia $28,31,32,34,35,36,38,41$

livros didáticos de ciências/biologia 28

M

manifestações culturais 65,66

materiais didáticos 14, 20, 22, 25, 31, 52, 62, 63

materiais poliméricos 53

mecanismos biológicos 113

medicamentos $42,43,44,58$

meio ambiente $65,69,77,78$

meiose $71,101,114,116,117,118,119,124,125$

Mentimeter 87, 88, 89, 92

Metodologias 14, 18, 65, 95, 96

metodologias ativas $14,87,89,90,91,94,96$

métodos profiláticos 20 
microestruturas 53,55

minimizar prejuízos 11

Ministério da Educação 11, 88

Ministério da Saúde 11

modelos didáticos 24, 98,100

modo de transmissão 20,22

mudanças no âmbito educacional 87, 88

$\mathbf{N}$

nano- e micropartículas 42

nanosistemas 42

nanotecnologia $43,50,53,54,55,56,57,58,61,62,63,64$

nanotecnologia e suas aplicações 54, 57, 62

natureza da ciência (NdC) 28, 29

novo coronavírus 87,88

O

oficinas de versificação 65

$\mathbf{P}$

Padlet 87, 88, 89, 92, 93

padrões de herança 98, 100, 101, 103, 110, 111

pandemia $11,12,14,17,18,87,88,89,96$

pandemia do COVID-19 11, 14

panfletos informativos 20

participação ativa $14,62,87,91,92,93,94,95$

participação mais efetiva 43, 44, 51, 62

Pecha Kucha 87, 88, 89, 90, 91, 92, 93

perspectiva cidadã 127

perspectiva sociocultural 127

plataformas digitais 11,15

polissacarídeo natural 44, 53, 55

poluição $55,65,69,70,82$

povo nordestino 65

principais dificuldades 11

problematização 28, 129, 134 
processo da fecundação 98,101

processo de ensino-aprendizagem 20, 25, 39, 52, 87, 100, 115, 124

professor de biologia 114,125

protozoário Entamoeba histolytica 20, 21

R

recursos didáticos alternativos 19,100

relação ecossistêmica 76,80

responsabilidade com o ambiente 76,84

$\mathbf{S}$

segurança $11,12,81$

simulações 98, 123

sobrevivência $76,78,79,80,83$

subsistência $76,77,79,80,82,83,84$

sub terapêutica 42

suspensão das aulas presenciais 11

sustentabilidade $65,69,71$

T

Tecnologias Digitais de Informação e Comunicação (TDICs) 87, 89

teoria celular $28,31,32,37,38$

terapêutica 42,49

Trilha da aprendizagem $87,89,90,92$

$\mathrm{U}$

uso de jogos 98

V

vírus SARS-CoV-2 11,12

$\mathbf{Z}$

zoologia 65,70 
